\title{
Chapter 9 \\ Conclusion: Divergences or Convergences? Facilitating Active Citizenship Through Adult Education Across Europe and Beyond
}

\author{
Hanna Toiviainen, Natasha Kersh, George K. Zarifis, and Pirkko Pitkänen
}

\section{Introduction}

By scrutinising a multiplicity of adult education policies, programmes and actions this book has sought answers to the question: What policies and practices are needed in the field of adult education to include young adults at risk of social exclusion in active participatory citizenship in Europe? Answers to the question were sought analysing the recent policy and practice developments in the field of adult education, social inclusion and active participatory citizenship both within the national, European and wider contexts. Each contribution in this volume has approached the question from original social and educational starting points. The findings of the EduMAP research presented in the chapters indicate that the cultural-historical contexts reflect country- and region-specific developments of social inclusion of young adults who live in vulnerable situations and are at risk of marginalisation. In the following sections we draw different lines together and discuss the findings from the perspectives motivating the EduMAP study. The perspectives stem from the discourses on lifelong learning (LLL) and adult education (AE); adult education as a means to prevent social exclusion; and the implications of this book in terms of the dimensions of active participatory citizenship (APC).

The seven region-specific contributions (Chaps. 2, 3, 4, 5, 6, 7 and 8) have highlighted both challenges and strategies of adult education across selected European countries and Turkey related to the inclusion of young adults. Social inclusion, as

H. Toiviainen $(\bowtie) \cdot$ P. Pitkänen

Faculty of Education and Culture, Tampere University, Tampere, Finland

e-mail: hanna.toiviainen@tuni.fi

N. Kersh

UCL Institute of Education, London, UK

G. K. Zarifis

Department of Education, School of Philosophy and Education, Faculty of Philosophy,

Aristotle University of Thessaloniki, Thessaloniki, Greece 
discussed in this volume, is strongly related to three dimensions of participation: socio-cultural dimension, socio-economic dimension and politico-legal dimension, which together have been highlighted as essential elements of active participatory citizenship.

The findings of EduMAP show that the configurations of and approaches to inclusion vary from context to context. Different forms of adult education (e.g. vocational education and training (VET), second-chance and basic skills programmes) were identified as a means to engage and re-engage young adults at risk of social exclusion, improve their life chances and facilitate their social inclusion, thus contributing to their capacity to take a more active role as citizens within their societal contexts. However, some serious challenges associated with addressing the specific educational needs of many vulnerable groups were highlighted within the national and cultural contexts of various countries and regions.

Within EduMAP, analyses of existing research and policy reports as well as educational practices enabled the researchers to consider relevant trends in country- and region-specific contexts and reflect on both convergences and divergences in the developments of adult education and lifelong learning across Europe and in Turkey. In the grouping of the countries stemming from the original project plan of EduMAP, we have utilized the notion of the "regimes of social cohesion" (Green et al. 2009) to provide meaningful points of comparison. We start by brief summaries of regional-specific notions that present the divergences. It is followed by a discussion revisiting the central perspectives - convergences and divergences drawn from the analyses. The key conclusions in the end focus on the possibilities of developing active participatory citizenship through adult education. It summarises the general notions, the convergences, underpinning the findings of the studies in this book.

\section{Regional Divergences}

\section{Southern Europe - Greece, Cyprus, Malta, Italy, Spain and Portugal}

Adult education (AE) developments in the Southern European and Mediterranean countries have been affected by a number of challenges stemming from the current economic, political and social situation in the region. As Chap. 2 indicates, overcoming the economic crisis has become one of the major challenges for $\mathrm{AE}$ in these countries. What is more, due to their geographic location, the Southern European states have been experiencing the consequences of the migration and refugee crisis, which has also resulted in demographic changes across the countries. Because of this situation, migrants and refugees have become a key target group for educational initiatives that focus on inclusion and integration, and this creates some additional challenges. The needs of these groups differ from the needs of the "traditional" key groups, which causes providers to make a great effort in re-structuring measures of programmes and organisations. 
As a result of the economic crisis in many Southern European countries, youth unemployment rates are extremely high, as well as the number of school dropouts or NEETs. In addressing these problems vocational education and training (VET) is playing an increasingly significant role in (re-)integration and re-engagement of young adults and improving their life chances: all Southern European countries have been noted to be developing and implementing methods and programmes that are tailor-made for young unemployed adults. However, there is a need to improve the correlation between education and training and the labour market. An emphasis on second-chance education as well as on recognition and validation of non-formal learning is another trend that has been noticeable in the context of developing opportunities for motivating and engaging vulnerable young adults. The programmes to include young adults across these countries have exemplified an indirect rather than direct relevance to active citizenship, and, the process has been characterized by rather low participation rates among vulnerable young adults in the region. As Zarifis' account shows (this volume), unemployed, low-qualified young adults in Southern Europe are largely under-represented with respect to participation in adult education programmes that focus on active citizenship.

\section{France, Austria and Germany}

The traditions of Adult Education (AE) in these countries have their roots in the Age of Enlightenment. Due to different historical and contemporary traditions, the interpretation of $\mathrm{AE}$ and Lifelong Learning (LLL) varies from country to country. However, EU policies and developments have strongly influenced national developments in AE in these countries, specifically by promoting a common legal and policy framework in the field of AE and introducing the concept of LLL (Evans 2009; Saar et al. 2013; Jarvis 2012). National AE initiatives and programmes are often addressed to the vulnerable groups of society, with the aim to bolster social inclusion, but different types of vulnerability are not always associated with a specific age group. Traditionally, the distinction made between formal and informal $\mathrm{AE}$ has been on the basis of types of institution (e.g. formal schools/institutions, Vocational Education and Training/Higher Education centres vs. outside institutions) or purposes of programmes (e.g. qualification purpose or life-oriented, general AE).

Research has shown that the common trends of contemporary developments and policies of AE have included tendencies towards strong market orientation (and less needs-driven education) and orientation towards employability. Increasing nonformal and informal learning offers, specifically for vulnerable young adults, has also been a prominent feature of the current movements in education in these countries. What further unites the developments is the need to address the problem of refugee and migrant inclusion. Research has indicated that informal (non-institutional) offers often relate to self-organised, volunteering actions that play an 
increasingly important role in civic education. In Germany, Austria and France, this has resulted in a high number of courses for migrants and refugees. In general, the higher number of learning offers and opportunities for vulnerable groups have been provided in the VET sector and in a wide range of informal learning offers across the countries.

\section{UK, The Netherlands and Ireland}

The studies suggest the increasing role attached to Adult Education (AE) and lifelong learning, specifically for facilitating the inclusion and engagement of vulnerable young adults. Overall, these countries have exemplified the fairly well-developed systems and structures of AE. In spite of existing diversities in both historical and contemporary policies as well as conceptions regarding AE across the UK, Ireland and the Netherlands, there are some shared developments in relation to policies and practices for the social inclusion of vulnerable young adults, influenced by both the economic and the social challenges currently faced by European countries. The countries have illustrated noticeable trends towards the focus on socio-economic participation, developing employability skills and tackling early school leaving. The problems of the young people grouped as 'NEET' (not in education, employment or training), and engaging this group through developing relevant labour market skills, has been specifically emphasised by the UK and Ireland contexts.

The situation of young migrants provides specific challenges in the Netherlands, which has resulted in the development of a range of programmes for inclusion. While some programmes are specifically focused on citizenship across the countries (e.g. programmes for migrants and refugees), often the concept of citizenship is not used explicitly but may be embedded in a wide range of other programmes (e.g. ESOL in the UK, Dutch as a second language NT2). European initiatives (e.g. Youth Guarantee) have also influenced country-specific implementation, with a particular focus on some new and existing education and training opportunities for young adults.

Common approaches in tackling issues of social exclusion and enhancing individual life chances are represented by remedial, retraining and basic skills courses aimed to provide learners with skills as well as a formal qualification/certificate. Informal learning has been recognised as a means of facilitating inclusion; however, there were concerns that non-formal and informal education provision (e.g. community education) and universal education services are being neglected over more 'targeted' formal programmes. Strategies and approaches towards the inclusion of vulnerable young adults across the countries have been influenced to some extent by global developments; however, the implementation of special programmes has been strongly related to national, local and regional challenges, problems and concerns. 


\section{Turkey}

The developments of AE in Turkey have been strongly affected by the influx of Syrian refugees as well as by the unstable political and social situation. The study of Turkey demonstrates that Syrian refugee inflow posed a major challenge for every aspect of public administration as well as the education system. While the 'traditional' vulnerable groups are recognised as such in the Turkish context (e.g. women, disabled individuals, school dropouts, ethnic minorities), the past 5 years have seen an increasing focus on the millions of Syrian refugees. In addition, as in Southern Europe EU countries, gender inequities have been noted as one of the challenges in Turkey that need to be tackled throughout AE programmes.

\section{Northern Europe - Denmark, Finland and Sweden}

Denmark, Finland and Sweden are Nordic welfare states that historically have put a high value on education as a means to increase equality in the society and providing support for those in need and for special groups and minorities. The Grundtvigian folk high school movement in the early history of liberal-popular AE targeted young adults, and this institute still prevails in non-formal education assuming new societal tasks, such as the integration education for migrants and asylum seekers. The adult educational ethos is today increasingly facing the dominance of the liberal market economies. Generally in all Nordic countries, budget cuts have affected particularly non-formal AE while resources have increased on formal AE of guidance and counselling, transition from basic to upper secondary education and training, one-step-up activities for the low-skilled, continuing training for the workforce, and preparing courses for immigrants ranging from elementary to higher education.

The countries aim to fulfil the EU Youth Guarantee through various initiatives. For Denmark, education is a special focus of the Danish policy concerning unemployed people below 30 years. Finland has launched one-stop guidance centres for youth, which aim to strengthen and simplify services for young people and to eliminate the duplication of activities. Sweden is introducing a 90-day guarantee of education or employment, to address the challenges relating to unemployment of low-skilled young people.

\section{Hungary}

Meeting both the democratic changes and needs of a market economy has been a notable development that was strongly related to overcoming unemployment and the reduced economic activity of the adult population. After the collapse of the Soviet Union, the former Socialist countries experienced a high degree of 
uncertainty and unstable social, political and economic situations. This has resulted in rising numbers of early school leavers, adults with deficiency in basic skills as well as minorities, experiencing difficulties in communication and integration, such as, for example, the Roma. These groups, together with other types of vulnerable adults have been affected by social exclusion and marginalisation. Addressing their needs was regarded as an important trend, following the stage of revitalisation of AE in the 1990s and the later EU accession. In recent years, the principles of AE policy and the interpretation of LLL have been largely determined by European integration. In Hungary the developments have been hindered by problems, such as the wave of emigration as well as the ageing society, largely resulting in a drop in the size of the potential workforce. This labour shortage provides a focus on the training and retraining of unemployed and inactive persons.

\section{Baltic Countries - Estonia, Latvia and Lithuania}

Estonia, Latvia and Lithuania have largely adopted the European concepts of AE and LLL. Despite of historical and regional closeness these Baltic countries have undergone different $\mathrm{AE}$ developments after regaining their independence. In the national acts and agendas of the Baltic countries the national language space protection is highlighted, but also means for bilingual AE opportunities combined with the social and cultural cohesion agendas and ecological sustainability means are used.

In Estonia, the market and job-related goal of AE and LLL prevail and the AE focuses on continuing education and on the job training models. Other trends are flexible transfer between study levels, bringing NEET to education and work, and social cohesion programs. There is lack of attention to informal education; the selfdirected educational development is underestimated compared with job-related development. Estonia has developed digital service provision that enables discovering the sets of constraints and requirements for supportive allowances, but it is not yet possible to filter the prerequisites of AE services for vulnerable young groups.

In Latvia and Lithuania, the steps have been made to move from adult education to education for adults concept, which also sees the self-development in civil society as part of AE goals. Latvia has introduced opportunities for young vulnerable adults, but active changes are obviously taking place age-independently in on-thejob training, second chance education, and validation of non-formally obtained competences. Lithuania has enacted laws and programs targeting informal learning to approve obtained competences, and informal education is seen as the tool for aiding vulnerable groups in the state agenda. These are not necessarily age-specific so as to reach young citizens. 


\section{Summary}

The contributions of this book emphasise both the significance of and the problems associated with lifelong learning and adult education, specifically in relation to facilitating the social inclusion of vulnerable young adults. Both historical developments and national approaches and conceptions towards AE and LLL indicate a range of country- and region-specific variations and divergent historical trends and priorities in LLL and AE. Countries with long-established traditions in Adult Education, such as the German-speaking countries as well as France, can trace the origins of $\mathrm{AE}$ to the Age of Enlightenment and Industrialisation. In Nordic EU-countries, Denmark, Finland and Sweden, some significant societal actors of liberal AE were born already towards the end of the nineteenth century in connection with national movements. Education in folk high schools of this early phase was targeted at countryside young people who lacked access to academic schooling. The historical developments of LLL and AE in the three Baltic States has been influenced by their Soviet heritage facing the issues associated with the period of transition from centralised economy to market economy, from a segregated society to the integration in all three countries after regaining their independence in the early 1990s. Some other countries of the Southern region, for example, Greece and Cyprus, have a relatively short history in terms of developing education for adults.

It has become evident that the adult education systems differ regarding the recognition and identification of vulnerability of young people. In some countries it is pointed out that vulnerability is age-independent, whereas in other countries sophisticated educational offering and programmes to young adults have been developed for years. Examples of the former can be found in the accounts of Austria, Germany and Greece, and examples of the latter case are Denmark, Finland, Sweden, UK, and Ireland. The interpretation of the concept of vulnerable young adults has also been strongly influenced by both historical and contemporary developments as well as national conceptions. The research undertaken and reported in this book largely suggests that vulnerable or disadvantaged young adults have been regarded as those who lack some essential capacities or are in need of being engaged or re-engaged in relation to social, political and economic involvement. Typically both the lack of capacities and weak social engagement of young adults require specific approaches in education and training.

Moreover, local or regional developments influence the identification of specific target groups of AE in each country or region. In the UK and Ireland, for example, a high number of young people who are classed as NEET have been defined as a group with particular needs of being integrated into the world of work or education. In Turkey, political unrest and military conflict in neighbouring countries has resulted in a high number of refugees and migrants, with the number of immigrants estimated to be over 4 million. The influx of refugees has characterised, to a greater or lesser extent, a range of other EU countries, and thus 'refugees and migrants' have been considered as a group of vulnerable people whose specific requirements 
need to be addressed in order to facilitate their social engagement, integration and inclusion.

\section{Discourse of Neo-liberal Life-Long Learning and Adult Education - Are There Alternatives?}

In the critical adult education discussion the juxtaposition of neoliberalism and community-based liberal AE tradition is an overarching theme. The critics that have outlined the narrative of neo-liberal hegemony on LLL and AE are well-grounded particularly in revealing how market logics and state regulation extend not only to formal but also non-formal and informal activities of adult education (Guimarães and de Castro 2009). For example, the analysis of the study associations in Sweden (Åbeg 2013) shows that the organisations adapt to regulation while on the other hand struggle to be true to their popular movement heritage. The organisations import concepts and solutions connected to commercialisation and professionalisation but may simultaneously strive for officially distancing themselves from commercialisation processes (ibid.). The question remains whether it is possible to resist the politically and socially normalised neo-liberal notions of qualifications, competence-based curricula, institutional reputation and expert labour (Zarifis 2019). The debate on the new role and the resistance of European adult education (Tet and Hamilton 2019) echoes researchers' and practitioners' awareness of the contradictory ideas of active citizenship as articulated in the European policymaking, on the one hand, and the pedagogical heritage of adult education, on the other hand.

Being caught between contradictory interests and struggling to maintain the cultural-historically rooted identity of adult education causes "breaches" of activity that open possibilities to expand the policies and practices of adult education and lifelong learning. Particularly when addressing adult education for vulnerable groups of young adults it is necessary to investigate the practices beyond the narrow socio-economic definition of adult education (Huegler and Kersh, this volume). This book has searched education practices and weak signals of education policies to meet the educational needs of precarious groups in Europe. Thus, in their analysis on the UK, the Netherlands and Ireland Huegler and Kersh reveal how the policy dynamics in the context of the economic crisis and austerity measures tend to focus on the responsibilisation of young people rather than structural reform of educational system. These policies are reflected in the professionals' work on local level where they face the needs of the young who experience unemployment or are classified as 'NEET', or young with migrant background. The professionals respond by personalised, flexible and empathetic support based on respectful relationships; they may enhance social integration, activism and mutual solidarity much beyond the assigned tasks of education and training (Toiviainen et al. 2019).

Pata et al. (this volume) see trends to the discourse that embraces more holistic adult education policy in the Baltic states. The end of the Soviet era meant a breakdown of the dominating ideological narrative of "nation of students" and the neoliberal turn in overall thinking and policies took over. They point out that the suggested conceptual shift from "adult education" to "education for adults" is to 
strengthen the goal of persons' self-development in building the civil society in Latvia and Lithuania.

Kuusipalo et al. (this volume) discuss that new adult educational trends and needs build on existing structures of civil society, legislation, educational provision and resources. Integration programmes and second-chance education can be seen as enhancing equal opportunities. A closer look at the programmes reveals small-scale innovations that not only aim at a quick (and often unrealistic) employment but a better social integration in local communities.

Zarifis (this volume) discusses the developments of adult education and social inclusion in southern European member states. In Portugal the stress upon economic development has reflected the ambivalence of the role assigned to adult education, diminishing it to a minor position in the political, social, educational, cultural and civic agenda. In addition, the emphasis on vocational education hampers the awareness of the importance of young adults' non-vocational learning.

The critics of neoliberalism and neoliberal economic interests that extend their hegemonic power to education and humanistic disciplines is directed at formal adult education and education policy on national and European levels. Non-formal and informal actions of adult education are not detached of economic-political regulation. The dominating discourse deals with educational policy issues as embedded in wider political-economic agendas, while overlooking that in major transformations adult education also produces grassroot movement and assumes new working methods. Our field studies show that there is space for learners' and educators' agency and volition to build human capacity and resist the instrumentalisation of vulnerable groups. In the global historical perspective this has been and still is the inalienable societal task of adult education (e.g., MCGray 2015).

\section{Adult Education as a Means to Prevent Social Exclusion - Expectations and Reality}

This book has explored the link between adult education and citizenship learning by indicating a positive movement for enlarging the understanding of lifelong learning from the limited focus of economic development to personal, social and democratic development through active citizenship. Nevertheless, a strong case still needs to be made for adult citizenship learning or for lifelong learning for active citizenship. A further enlargement of minds, policies and practices is necessary to widely share and strengthen the citizenship dimension. The objective should be to lift the contradictions, to clarify, focus and exemplify statements and data. There is a need to go "beyond the rhetoric".

While there are strong claims and expressions for a comprehensive approach to lifelong learning aiming at both employability and personal, social and democratic development, the practices continue to show an inclination for the former rather than the latter. Another encouragement in favour of the active citizenship approach to lifelong learning comes from discussions on how to make learning attractive and the identified need for developing a new learning culture. Even though the trends of neoliberalism and increasing state regulation can be observed across countries and in adult education policies implemented in various regions there are significant 
differences regarding the needs and even more so regarding the outcomes of the intended policies. This can be seen in answering the educational needs of refugees and asylum seekers where alone the scale of the task is dramatically different and unevenly shared between the south-east and northern parts of Europe.

In Turkey the researchers (Erdoğan et al. this volume) follow the developments of the integration of refugees by means of adult education and holistic approaches of social work. The outcomes of the work under onerous conditions must be considered successful, while at the same time it is obvious that not all goals to prevent social exclusion can be reached. The situation of refugees is instable, the ethos of adult education as a means of equal opportunity meets the requirements of genderspecific and -limited options; conception of education addressing temporary migration must be further defined when temporariness turns to permanent residence for some, etc.

Organising adult education for groups recognised as vulnerable appears very differently depending on the social and political programmes and existing educational infrastructures and even the cultural-historical developments and backgrounds. The most striking example is presented by the Hungarian researchers Tóth et al. (this volume). They perceive the adult education and learning in EU positively as the field of individual self-fulfilment and the improved adaptability to globalization and democratic values, and then contrast these trends with the social development of the region in terms of autocratic inertia and identity/sovereignty fear amidst globalisation. "Hungary has moved away from the international trend, returning to a nonmarket-driven, indoctrinating, legally over-regulated system," they argue and present extensive data to show how the educational needs of vulnerable groups are overlooked in the political reality unveiled.

In Southern Europe (Greece, Cyprus, Malta, Italy, Spain and Portugal), adult education, in a historical perspective, does not play a leading role as a means to social inclusion and active citizenship (Zarifis, this volume). Therefore the expectations on the possibilities of AE will have to be politically enhanced and socially constructed in the value system. According to the researcher the key is the development of competence-based AE programmes that appeal to young learners as well as local societies and are strong enough to build the connection between education, social inclusion, most of all in terms of employment, and active participatory citizenship.

Recommendations drawn from all the chapters imply that policy focus needs to be re-calibrated to include both the pressing economic and employment challenges and the role of education in promoting equity and inclusion. Active citizenship entails setting new priority areas that stretch from high-quality knowledge, skills and competences developed throughout lifelong learning, to inclusive education, equality, equity, non-discrimination and the promotion of civic competences. For adult education and training in particular priorities should include more effective governance, significant increases in supply and take-up, more flexible provision, broader access, closer monitoring and better quality assurance.

The citizenship potential was highlighted in most of the studies, often not by recognising it as such, but as a dynamic process that must be continuously 
encouraged through a learning-conducive environment. Besides focussing on the learners' needs and motivation this includes the pedagogic support to the participants to engage in critical thinking, acting in an autonomous and responsible manner, and orienting to learning together and social participation.

The crucial question however is how these priorities can be achieved. "Ensuring that children and young people acquire social, civic and intercultural competences, by promoting democratic values and fundamental rights, social inclusion and nondiscrimination, as well as active citizenship" (EU 2015, p. 4) is of little help to people who work in the field to achieve what the rhetoric prescribes. The arrival of refugees and asylum seekers with diverse backgrounds is creating a challenge for the education and training sector and its stakeholders throughout Europe. The integration of these people into education and training is a crucial step towards their social inclusion, employability, professional and personal fulfilment, and active citizenship (Bagnall 2010).

\section{Active Participatory Citizenship for the Future? Key Conclusions}

Social exclusion and alienation are real problems among many young people of minority groups living in a hybrid space between the mainstream and peripheral cultures. Learning in adult education settings plays an essential albeit only a partial role in creating proper preconditions for social membership and full attention to cultural diversity. Learning for active citizenship is a lifelong and changing process starting already in childhood (Kalekin-Fishman et al. 2007). Several questions and challenges arise regarding the prevention of social exclusion. What policies and practices are used to foster active participation and a sense of citizenship through adult education? What should the key elements in education be as far as vulnerable groups are concerned?

Reflecting on the findings of the EduMAP research we are convinced of the key role of the adult education policies and practices in recognising young adults' needs in the living communities of European countries and Turkey (EduMAP 2018, 2019). The research results also demonstrate that the way from the risk of social exclusion to active participatory citizenship is complex, still largely unmapped and calls for more research. As the study in Germany by Endrizzi and Schmidt-Behlau (this volume) most clearly articulates, the notion of active participatory citizenship can be explicitly designed in an education strategy, but often is an implicit intention; it is on the cover and undercover. In addition, active participatory citizenship for young adults living in vulnerable situations is promoted in many contexts, such as the Youth Forum in Germany - not only within the identified systems of adult education.

The divergences in the perceptions and policies of effective adult education for vulnerable young adults are attributed to the difference in the historical trajectories and contemporary local challenges of countries and regions. The convergences and common trends in the provision of adult education for vulnerable young people have been influenced in many ways by common global challenges, EU policies and research in the area of adult education and lifelong learning (EduMAP Policy Brief 12018 ). In conclusion, some overarching notions and convergences across national trends can be pointed out. 
1. The concept of active citizenship (AC) is used across the EU countries and Turkey with different aims, purposes and interpretations. Policy agendas and country-specific priorities - rather than universally shared human values define overall objectives and the meaning of active citizenship and the role of education and its promotion.

2. The lack of clarity and definitions of $\mathrm{AC}$ in the adult education and lifelong learning literature and policy actions make the understanding, interpretation and role of citizenship/active citizenship somewhat fragmented and patchy, and the concept varies from context to context both nationally and internationally. The controversies and broad interpretation of AC calls for in-depth empirical research to explore the complexity of relationships between adult education, active citizenship and social inclusion.

3. The reviews of research and policy analysis also indicate that the concept of adult education and lifelong learning remains poorly defined and open to various interpretations and, often, with no explicit link to active citizenship.

4. The role of adult education practices in promoting active citizenship for vulnerable groups is unclearly defined across the national adult education systems. Engaging vulnerable young people through adult education has been related to addressing specific problems (e.g. poor literacy level or unemployment), defined by current national political, social or economic agendas.

5. With the exception of programmes for newly arrived migrants and/or refugees, the majority of adult education courses do not demonstrate an explicit focus on citizenship education or skills. However, different dimensions - economic, social and political - of active participatory citizenship have characterised, often implicitly, AE programmes and initiatives across the studied countries.

6. While some programmes are specifically focused on citizenship (e.g. programmes for migrants), the concept itself remains often weakly explicated or embedded in other objectives of a given education. When included in AE programmes, the dimensions of active participatory citizenship (economic, social and political) are often driven by current national policy developments and agendas, rather than by the specific needs of disadvantaged groups.

7. The analyses of AE programmes confirm that the developments and policies of the past decade related to adult education and active citizenship have been strongly influenced both by economic crisis and the influx of migrants across the EU countries and Turkey. These trends have resulted in the prevalence of market-oriented approaches and the integration strategies across adult education programmes.

8. Different types of adult education have become important tools for engagement and (re)integration of young adults into society. The role of AE has largely been associated with providing opportunities for young adults to acquire the range of skills required in order to participate in social, economic and political life. Practically all country-specific studies brought out the significance of the following types of programmes: 
1. Basic skills and remedy programmes

2. Second-chance education

3. Retraining

4. Vocational programmes

5. Informal learning and non-formal learning

6. Selected higher education programmes

9. Investigated in the context of adult education, the term 'vulnerable young adults' remains open to various interpretations. The desk study of documents and even more the oral interview statements by practitioners, policy-makers and young people reveal how different perceptions of vulnerability there are among the stakeholders. For policy-makers the notion of vulnerability may be necessary to address the special target groups in education, whereas practitioners may avoid the use of the term as a labeling one, and still young people may not identify themselves as being vulnerable or in a vulnerable situation, at the outset.

10. Gender is not generally perceived to be a vulnerability, concluding from the studies of this book. There are few gender-specific programmes that focus on the promotion of active citizenship. However, research indicates that in some contexts young adults need specific extra support on account of their gender, which comes out clearly in the chapters from Turkey and the Mediterranean region. Gender differences need to be taken into account in the design of future adult education programmes on national and transnational level.

The research findings, highlighted by the country-specific accounts, underpin two significant conclusions. First, the analysis has indicated that, overall, young adults in diverse situations of risk have positive experiences related to recovering motivations and engaging actively in society by way of attending adult education programmes. The second point, however, is that the providers need to understand and take into account in developing their policies and practices, that engaging young adults through adult education needs to be based on their multi-layered individual needs thus promoting more and deeper active participatory citizenship (APC) engagement (Schmidt-Behlau 2019). Therefore, policies, programmes and actions need to pay attention to young learners' specific needs, aspirations and risks of vulnerabilities.

The elements of successful policies and practices in re-engaging young people strongly relate to addressing young adults' specific needs and facilitating their APC, rather than just focusing on addressing current policy agendas (EduMap Policy Brief 2 2019). The cross-cutting elements of meaningful policy and practice approaches, should include the following: (1) relevance and contextualisation: e.g. contextualising APC dimensions in ways that are relevant to young adults' personal backgrounds and/or professional aims, ambitions, and gender differences need to be taken into account; (2) opportunities and affordances: creating opportunities to exercise active citizenship in all its dimensions and related to young adults' experiences and personal situations; (3) flexibility and personalisation rather than 'one size fits all' approach: ensuring flexible provision that provides personalised approaches in developing educational programmes; (4) the significant role of the 
educational professional: the importance of the mediating role of educational professionals needs to be better recognised and taken into account by relevant stakeholders (5) multiculturalism and tolerance: promoting learning in diverse and multicultural groups in a safe environment; (6) resilience and confidence: fostering resilience, confidence, self-esteem and aspiration of young adults; (7) the role of communication networks: promoting communication between different stakeholders. This list is not exhaustive, but it highlights the most commonly cited elements of good practice across country specific contexts. Favourable and supporting policies that recognize vulnerabilities as complex and multifaceted issues, avoid policy responses to put 'blame' on individuals (e.g. refugees, in countries affected by refugee crisis, migration or acts of terrorism) and ensure issues of equality and equal access to resources provide a wider context for successful inclusion approaches.

Finally, it is important to consider the historical development and unique legacies in and across the countries. Initiatives that work well in one country may need adjustments when adopted in another. Policy-learning rather than policy-borrowing is at stake. The first approach supports the development of national policies suitable for specific contexts, whereas the latter refers to adopting practices developed in other countries 'off-the-peg' (Raffe and Semple 2011). This distinction is critical for policymakers in assessing what practices can have a positive impact in their educational contexts and under what conditions.

In considering the interplay between policy and practice the contributions in this volume bring attention to the ways in which policy and practice developments may either undermine or contribute to cultivating active participatory citizenship for young adults, and what might be learnt from these developments. As part of the EduMAP project's ambition, the research findings aim to contribute to the complex discussion of the current and future role of adult education as a means to social inclusion, and to advance understanding and further develop both the current and future impact of adult education on learning for active participatory citizenship in Europe and beyond.

\section{References}

Åberg, P. (2013). Managing expectations, demands and myths: Swedish study associations caught between civil society, the state and the market. Voluntas: International Journal of Voluntary and Nonprofit Organizations, 24(3), 537-558. https://doi.org/10.1007/s11266-012-9271-3.

Bagnall, R. (2010). Citizenship and belonging as a moral imperative for lifelong learning. International Journal of Lifelong Education, 29(4), 449-460.

EduMap Policy Brief 1. (2018). Broad research of European adult education for young adults at risk of social exclusion: Perspective of active participatory citizenship. https://projects.tuni. fi/edumap/policycorner/edumap-recommends-to-pay-attention-to-vulnerable-young-learnersneeds-and-to-set-explicit-goals-policy-brief/. Accessed on 21 Feb 2021.

EduMap Policy Brief 2. (2019). Good Practices of adult education for young adults at risk of social exclusion: Towards active participatory citizenship. https://projects.tuni.fi/edumap/policycorner/edumap-policy-brief-updates-published/. Accessed on 21 Feb 2021. 
Endrizzi, F., \& Schmidt-Behlau, B. (this volume). Active participatory citizenship for and with young adults in situations of risk - On the cover and under-cover. In N. Kersh et al. (Eds.), Young adults and active citizenship, Lifelong Learning Book Series 26. Cham: Springer.

Erdoğan, A., Unutulmaz, K. O., Aydemir, S. G., \& Erdoğan, M. M. (this volume). How are the prospects for refugees to become active members of society? - The vision and practices in Turkish adult education. In N. Kersh et al. (Eds.), Young adults and active citizenship, Lifelong Learning Book Series 26. Cham: Springer.

EU Ministries of Education. (2015). Declaration on promoting citizenship and the common values of freedom, tolerance and non-discrimination through education. Informal Meeting of European Union Education Ministers. http://ec.europa.eu/assets/eac/education/news/2015/ documents/citizenship-education-declaration_en.pdf. Last accessed on 29.02.2020.

Evans, K. (2009). Learning, work and social responsibility. Dordrecht: Springer.

Green, A., Janmaat, J. G., \& Han, C. (2009) Regimes of social cohesion, published by the Centre for Learning and Life Chances in knowledge economies and societies at: http://www.llakes. org.uk. Accessed 18 Aug 2020.

Guimarães, P., \& de Castro, R. V. (Eds.). (2009). The state, civil society and the citizen: Exploring relationships in the field of adult education in Europe (Vol. 6). Frankfurt am Main: Peter Lang.

Huegler, N., \& Kersh, N. (this volume). Social inclusion, participation and citizenship in contexts of neoliberalism: Examples of adult education policy and practice with young people in the UK, The Netherlands and Ireland. In N. Kersh et al. (Eds.), Young adults and active citizenship, Lifelong Learning Book Series 26. Cham: Springer.

Jarvis, P. (2012). Adult learning in the social context. London: Routledge.

Kalekin-Fishman, D., Tsitselikis, K., \& Pitkänen, P. (2007). Theorizing multiple citizenship. In D. Kalekin-Fishman \& P. Pitkänen (Eds.), Multiple citizenship as a challenge to European nation-states (pp. 1-38). Rotterdam: Sense Publishers.

Kuusipalo, P., Toiviainen, H., \& Pitkänen, P. (this volume). Adult education as a means to social inclusion in Nordic welfare states: Denmark, Finland and Sweden. In N. Kersh et al. (Eds.), Young adults and active citizenship, Lifelong Learning Book Series 26. Cham: Springer.

MCGray, R. (2015). Anti-austerity adult education in Canada: A survey of a nascent field. International Journal of Lifelong Education, 34(3), 251-267.

Pata, K., Maslo, I., \& Jõgi, L. (this volume). Transforming adult education from neo-liberal to holistically inclusive adult education in Baltic States. In N. Kersh et al. (Eds.), Young adults and active citizenship, Lifelong Learning Book Series 26. Cham: Springer.

Raffe, D., \& Semple, S. (2011). Policy borrowing or policy learning?: How (not) to improve education systems. Edinburgh: Centre for Educational Sociology.

Saar, E., Ure, O. B., \& Holford, J. (Eds.). (2013). Building a European lifelong learning society: National patterns and challenges. Cheltenham: Edward Elgar.

Schmidt-Behlau, B. (2019). Good practices in adult education programmes for young people in vulnerable situations; EduMap research report. https://projects.tuni.fi/edumap/publications/ deliverables-and-reports/two-edumap-reports-published. Last accessed on 23.12.2020.

Tet, L., \& Hamilton, M. (Eds.). (2019). Resisting neoliberalism in education: Local, national and transnational perspectives. Bristol: Policy Press.

Toiviainen, H., Kersh, N., \& Hyytiä, J. (2019). Understanding vulnerability and encouraging young adults to become active citizens through education: The role of adult education professionals. Journal of Adult and Continuing Education, 25(1), 45-64. https://doi. org/10.1177/1477971419826116. Open access: http://urn.fi/URN:NBN:fi:tuni-201903071320

Tóth, J., Szirmai, É., Merkovity, N., \& Pongó, T. (this volume). Promising or compelling future in Hungary? In N. Kersh et al. (Eds.), Young adults and active citizenship, Lifelong Learning Book Series 26. Cham: Springer.

Zarifis, G. K. (2019). Rethinking adult education for active participatory citizenship and resistance in Europe. In L. Tet \& M. Hamilton (Eds.), Resisting neoliberalism in education: Local, national and transnational perspectives (pp. 225-238). Bristol: Policy Press.

Zarifis, G. K. (this volume). Active citizenship programmes for unemployed young adults with low skills in Southern Europe: Participation, outreach, and barriers. In N. Kersh et al. (Eds.), Young adults and active citizenship, Lifelong Learning Book Series 26. Cham: Springer. 
Open Access This chapter is licensed under the terms of the Creative Commons Attribution 4.0 International License (http://creativecommons.org/licenses/by/4.0/), which permits use, sharing, adaptation, distribution and reproduction in any medium or format, as long as you give appropriate credit to the original author(s) and the source, provide a link to the Creative Commons licence and indicate if changes were made.

The images or other third party material in this chapter are included in the chapter's Creative Commons licence, unless indicated otherwise in a credit line to the material. If material is not included in the chapter's Creative Commons licence and your intended use is not permitted by statutory regulation or exceeds the permitted use, you will need to obtain permission directly from the copyright holder. 